\title{
Changes of right ventricular function with positive end-expiratory pressure (PEEP) in man
}

\author{
P. P. Neidhart and P. M. Suter \\ Department of Anesthesia and Surgical Intensive Care, University Hospital of Geneva, Genève, Switzerland
}

\begin{abstract}
The side effects of positive pressure ventilation on cardiovascular function are well known. However, in most clinical studies its influence on left ventricular function was examined. In the present study right ventricular (RV) performance was studied in 13 patients undergoing coronary artery bypass grafting during mechanical ventilation with and without positive end-expiratory pressure (PEEP). In the majority of patients $(10 / 13)$, PEEP caused a decrease in RV end-diastolic volume (by $18 \%$ ) whereas RV ejection fraction did not change. In the remaining $3 \mathrm{pa}-$ tients, end-diastolic and end-systolic RV volumes increased by $25 \%$ and $50 \%$ respectively and ejection fraction decreased by $29 \%$. These results suggest that PEEP can affect RV function in two different ways: first, in the majority of patients studied, PEEP exerted an unloading effect on the RV whereas second, in 3 patients RV dilatation and a decrease in ejection fraction was observed.
\end{abstract}

Key words: Positive pressure ventilation - Right ventricle - Thermodilution

Recently a rapid response thermistor mounted on a pulmonary artery catheter was developped, allowing the measurement of beat to beat temperature variations in the pulmonary artery. With this technique, right ventricular ejection fraction (RVEF) can be calculated from the thermal washout curve after injection of a cold liquid bolus in the right atrium $[2,6]$. The values of RVEF and of the simultaneously obtained stroke volume (SV) can then be used to calculate right ventricular enddiastolic and end-systolic volumes (RVEDV, RVESV) using the formulas

1. $\mathrm{RVEDV}=\mathrm{SV} / \mathrm{RVEF}$

2. $\mathrm{RVESV}=\mathrm{RVEDV}-\mathrm{SV}$
In order to assess the clinical implication to measure these RV function parameters in addition to the conventional hemodynamic variables, we studied patients during continous mechanical ventilation (CMV) with or without positive end-expiratory pressure (PEEP).

\section{Patients and methods}

Thirteen patients undergoing coronary artery bypass graft surgery with a mean age of $61 \pm 7$ years, were studied after anaesthesia induction (midazolam-fentanyl-pavulon) but before surgical stimulation. All patients were ventilated with the same volume controlled ventilator (Engström Erika). During successive periods of $\mathrm{CMV}$ with 0 end-expiratory pressure (ZEEP) and with a PEEP of $10 \mathrm{~cm} \mathrm{H}_{2} \mathrm{O}$, we measured cardiac output (CO) and RVEF with the thermodilution technique by injecting $10 \mathrm{cc}$ of iced $5 \%$ dextrose solution in the right atrium. The mean value of at least 4 sequential CO-measurements with a coefficient of variation below $8 \%$ was taken as the representative value during each ventilatory period. For each $\mathrm{CO}$ the corresponding stroke volume (SV), RVEF, RVEDV and RVESV were recorded and its mean calculated. At the end of the $\mathrm{CO}$ measurements a full set of hemodynamic variables (heart rate; systolic, diastolic and mean systemic and pulmonary artery pressure) was collected. End-expiratory carbon dioxide was measured throughout the study and held constant by adjusting the minute volume delivered by the respirator.

All results are expressed as the mean \pm one standard error of the mean (SEM). The CO and RV function parameters were indexed by dividing the mean of the measured values by body surface area. Percentage changes were calculated by taking the ZEEP value as $100 \%$. The Student's t-test for paired data was applied 


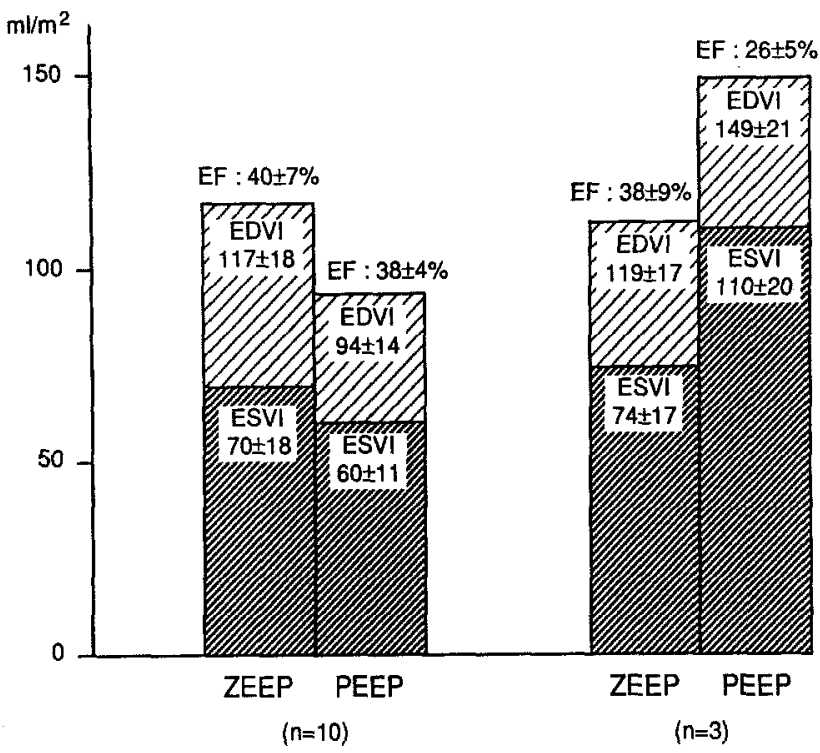

Fig. 1. Right ventricular hemodynamic parameters during IPPV and CPPV

to compare results during ZEEP- and PEEP-ventilation. A $p<0.05$ was considered to be statistically significant.

\section{Results}

In all patients studied, cardiac index (CI) fell during CMV+PEEP by a mean of $23 \pm 9 \%$ i.e. from a mean value of $3.0 \pm 0.5$ to $2.3 \pm 0.021 / \mathrm{min} / \mathrm{m}^{2}(p<0.001)$. Because heart rate did not change, the decrease in $\mathrm{CI}$ was due to a fall of the stroke volume index (SVI) from $46 \pm 7$ to $36 \pm 4 \mathrm{ml} / \mathrm{m}^{2}(p<0.001)$, equal to a change of $20 \pm 11 \%$. In the majority of the patients studied (10 out of 13) these decreases went in parallel with a reduction of the right ventricular end-diastolic volume index: RVEDVI fell from $117 \pm 18$ to $94 \pm 14 \mathrm{ml} / \mathrm{m}^{2}$ $(-18 \pm 8 \% ; p<0.001)$. These 10 patients were called "group A". In the remaining three patients (called group B), an increase in RVEDVI by $25 \pm 1 \%$, from $119 \pm 17$ to $149 \pm 21 \mathrm{ml} / \mathrm{m}^{2}(p<0.02)$ was observed. The RVEF in these three patients fell by $-29 \pm 9 \%$ from a mean value of $38 \pm 9$ to $26 \pm 5 \%$, whereas in the 10 other patients only a small decrease from $40 \pm 7$ to $38 \pm 4 \%$ was observed (Fig. 1). The difference in the mean percentage changes of the RVEF between the 3 patients in group B and the 10 patients in group $A$ was statistically significant $(p<0.02)$ (Student's test for non-paired data). Only minor changes in RVESVI could be observed in group A, namely a non significant fall from $70 \pm 18$ to $60 \pm 11 \mathrm{ml} / \mathrm{m}^{2}$ whereas in group B an increase from $74 \pm 17$ to $110 \pm 20(p<0.02)$ was found.
In both groups the mean increase in systolic pulmonary artery pressure during CMV+ PEEP was similar and significant $(p<0.02), 15 \pm 5 \%$ in group A and $16 \pm 18 \%$ in group B. All other measured hemodynamic and respiratory variables were similar in both groups throughout the study period and no significant difference could be found preoperatively in any clinical characteristic examined, namely numbers of coronary arteries diseased, extension of right coronary artery disease, left ventricular function tests.

\section{Discussion}

The adverse effects of CMV with and without PEEP on the cardiovascular system have been attributed to one or a combination of several of the following mechanisms interfering with RV function $[1,4,5]$ : (1) Decreased venous return and RV filling [8, 9]; (2) Increased RV afterload [3] with (3) Reduction in RV performance [7]; (4) Impairment of RV myocardial perfusion; (5) Ventricular interdependence.

With the advent of a pulmonary artery catheter with a rapid response thermistor a reproducible method to measure RVEF and its derived variables has become available [10]. We used this device to study the possibility to obtain useful clinical information about the nature of right ventricular function changes and its contribution to overall cardiovascular performance during CMV with and without PEEP.

In our study, PEEP caused a significant fall in CI and SVI in all patients. However the analysis of RV function revealed that this decrease was caused by two different mechanisms: (1) In the majority of the patients PEEP exerted an "unloading" effect on the RV, i.e. decreased RVEDVI without affecting its systolic function, whereas (2) in 3 patients evidence was present that PEEP caused RV dilatation and "depressed" myocardial function, suggested by the observed increase in RVEDVI and RVESVI as well the decrease in RVEF.

However although the mean percentage decrease of RVEF during CMV with PEEP was significant only in group B, this variable alone was of limited value to determine fully the degree of right ventricular dysfunction. Only by analysing the corresponding derived variables RVEDVI and RVESVI a clear distinction between group A and B patients could be made.

The reason why these RV function parameters behaved differently, is not clear. The most likely explanation, a different effect of PEEP on the pulmonary vascular resistance, was not corroborated by our results. Other possible reasons as for example severity of right coronary artery disease, effect of PEEP on left ventricular function, or intravascular 
volume status were measured or judged to be similar in both groups. However the small sample of group B patients may have not allowed to observe small differences in any of the mentioned variables.

In conclusion the bedside measurement of RV function parameters can contribute to determine the pathophysiology of the hemodynamic changes occuring during mechanical ventilation with and without PEEP. However further investigations are needed to assess the importance of RV function changes in view of possible therapeutic consequences.

\section{References}

1. Dhainaut JF, Devaux JY, Monsailler JF, Brunet F, Villemant D, Huyghebaert MF (1986) Mechanisms of decreased left ventricular preload during continuous positive pressure ventilation in ARDS. Chest 90:74

2. Dhainaut JF, Brunet F, Monsailler JF, Villemant D, Devaux JY, Konno M, DeGournay JM, Armaganidis A, Iotti G, Huyghebaert MF, Lanore JJ (1987) Bedside evaluation of right ventricular performance using a rapid computerized thermodilution method. Crit Care Med 15:148

3. Henning RJ (1986) Effects of positive end-expiratory pressure on the right ventricle. J Appl Physiol 61:819
4. Jardin F, Farcot J, Boisante L, Curien N, Margairaz A, Bourdarias JP (1981) Influence of positive end-expiratory pressure on left ventricular performance. N Engl J Med 304:387

5. Jardin F, Farcot J, Gueret P, Prost JF, Ozier Y, Bourdarias JP (1984) Echocardiographic evaluation of ventricles during continuous positive airway pressure breathing. J App Physiol $56: 619$

6. Kay HR, Afshari M, Barash $P$, Webber W, Iskandrian A, Bemis $C$, Hakki AH, Mundth ED (1983) Measurement of ejection fraction by thermal dilution technique. J Surg Res 34:337

7. Pouleur $H$, Lefèvre J, van Eyll C, Jaumin PM, Charlier AA (1978) Significance of pulmonary input impedance in right ventricular performance. Cardiovasc Res 12:617

8. Qvist J, Pontoppidan H, Wilson R, Lowenstein E, Laver MB (1975) Hemodynamic response to mechanical ventilation with PEEP: the effect of hypervolemia. Anesthesiology 42:45

9. Schreuder JJ, Jansen JRC, Versprille A (1985) Hemodynamic effects of PEEP applied as a ramp in normo-, hyper- and hypovolemia. J Appl Physiol 59:1178

10. Urban P, Scheidegger D, Gabathuler J,, Rutishauser W (1987) Thermodilution determination of right ventricular volume and ejection fraction: a comparison with biplane angiography. Crit Care Med 15:652

Dr. P. P. Neidhart

Department of Anesthesia

University Hospital of Geneva

$\mathrm{CH}-1211$ Genève

Switzerland 